\title{
Does nest site availability limit the density of hole nesting birds in small woodland patches?
}

\author{
J. Loman
}

Loman, J. 2006. Does nest site availability limit the density of hole nesting birds in small woodland patches? - Web Ecol. 6: 37-43.

\begin{abstract}
By providing nest boxes, previous studies have shown that nest sites are in short supply and limit the populations of several small passerines, including the Great Tit Parus major, the Blue Tit $P$. caeruleus, and the Pied Flycatcher Ficedula hypoleuca. Can this influence their distribution over a range of small woodland patch sizes in a heterogeneous landscape? To investigate this, a study was conducted in a heterogeneous agricultural landscape, with a mixture of wooded patches and cropped fields, in southern Sweden. The descriptive part of the study involved mapping territories of the three species in 135 patches. These species avoided small $(<1$ ha, Pied Flycatcher) or very small $(<0.2$ ha, the two tit species) forest patches in this landscape. In an experimental part, a subset of 34 patches, 0.01 to 24 ha in size was used. Territories were mapped in a first yr as a control. In a second yr, patches were matched by size and vegetation and nest-boxes were provided in one patch of each pair. Territories were again mapped. Providing nestboxes increased the density of breeding Great Tits in patches of all sizes and expanded their use of very small patches. The nest-boxes increased the density of Pied Flycatchers in large patches but not in small patches. So, is the lack of territories in small patches due to shortage of nest sites? The outcome of the experiment suggests nest site limitation as a cause of the observed Great Tit discrimination against very small habitat patches. The lack of Pied Flycatchers in small patches must however have another basis than lack of nest sites. The effect of providing nest-boxes on Blue Tit distribution was inconclusive.
\end{abstract}

J. Loman (jon.loman@zooekol.lu.se), Dept. Animal Ecology, Lund Univ., SE-22362 Lund, Sweden.

Modern landscapes are often highly fragmented (Angelstam 1992). For many species they consist of patches of semi-natural habitat of various sizes in a hostile matrix (Nilsson and Ericson 1992). In the south Swedish landscape, typical patches are wooded, and include small forests, tree rows and even single trees. The dominating matrix consists of cropped fields. A problem in conservation is to determine to what extent these small patches represent the habitat that originally covered the landscape (Nilsson 1986). Lack of representativeness can come from two causes. It may be that the small patches, on closer view, are different from the original habitat. Small forest patches may have a different set of tree species represented, compared to what is found in a natural climax forest. It may also be that patchiness per se, because of area and isolation effects, influences various processes such as breeding success, survival, habitat choice, and migration, leading to differences in the natural community of the patch compared to the corresponding natural habitat (Evans 2004). In addition, the view of the matrix as a desert is often an over- 
simplification, and the characteristics of the matrix may have important effects on the suitability of patches (Andrén 1994, Estades 2001).

As an example of effects of fragmentation, small woodland habitat patches in agricultural areas have indeed been found to contain restricted sets of forest bird species (Moore and Hooper 1975, Cieslak 1985, van Dorp and Opdam 1987, Bellamy et al. 1996, Hinsley et al. 1996, Kurosawa and Askins 2003). However, species diversity sometimes can be as high as that in larger patches (Blake and Karr 1984, Loman and von Schantz 1991, Berg 1997). In line with the reasoning above, this may be due to direct differences in the vegetation of small and large patches or it may be due to size and isolation per se. Holenesting birds may be limited by the availability of nest sites (Brawn and Balda 1988, Newton 1994, Bock and Fleck 1995, Thompson et al. 2002) and it may be that differences in tree species composition and tree conditions cause nest sites for hole nesters to be in short supply in small habitat patches.

The Great Tit (Parus major L. 1758), the Blue Tit (P. caeruleus L. 1758), and the Pied Flycatcher (Ficedula hypoleuca Pallas 1764) are three common hole nesters that readily accept nest boxes and tend to be missing from the smallest forest patches (Opdam et al. 1985, Hinsley et al. 1996, Huhta et al. 1998, Huhta and Jokimäki 2001). In this study, their use of small habitat patches in an area in southern Sweden is firstly analysed using a descriptive data set. Secondly, the hypothesis that nest sites are in short supply in small and/or medium sized habitat patches is tested experimentally by means of nest box provisioning.

\section{Study area and methods}

The study was conducted in agricultural landscapes in Skåne which is the southernmost province of Sweden.

\section{Descriptive study}

Great Tits, Blue Tits, and Pied Flycatchers were censused by means of territory mapping in a total of 135 wooded patches in south western Skåne in 1982 and 1983. Mappings were performed during 8 to 10 visits to each patch from April 21 to June 28. Birds observed (seen or heard) were scored on a map and the number of territories evaluated from these locations (Anon. 1970). The evaluation was based on clusters of locations and interpretation of behaviour like singing and territory disputes. It was assumed that no territory spanned more than one mapped island. Though in principle possible, this is very unlikely as most patches were at least $200 \mathrm{~m}$ from any other patch. Patch sizes varied between 0.01 ha and 24 ha. All patches used by the present study species were wooded (but in the case of the smallest ones it sometimes happened by only one tree).
This was part of a larger study reported by Loman and von Schantz (1991), where a fuller account of methods and study patches is given.

\section{Experimental study}

Nest-boxes were supplied in three areas in western Skåne. The three areas, which were a subset of those used for the descriptive study, are close to the estates of Svenstorp, Ellinge and Trolleholm. In these areas 20, eight, and six wooded experimental patches were used. All areas were dominated by cropped fields, woods making up less than $10 \%$ of the total area. In Trolleholm there was also about $30 \%$ grazed fields.

All experimental study patches were censused for breeding birds by territory mapping in 1983 (Anon. 1970). Half of these patches were supplied with nest boxes in the winter of 1984, and the census was repeated during the following spring. The nest boxes had an opening diameter of 26 $\mathrm{mm}$ or $32 \mathrm{~mm}$, (50\% of each). The former are avoided by Great Tits but used by Blue Tits (J. A. Nilsson, pers. comm). In patches over 1 ha in area, I supplied ten nestboxes per ha. In the smaller patches, I supplied two to five boxes. This meant that density in these patches was from 14 up to 200 boxes per ha in the smallest ones. A higher density was thus used in the smaller patches to assure that the number of boxes would not be limiting even if some individual boxes were disfavoured. The patches were divided into two groups with matching pairs. In each pair, one patch was used as an experimental patch and the other as control. The two patches in a pair were similar in size and habitat and situated within the same estate.

For the statistical analysis I used each patch as an independent unit. The response variable was the difference in number of territories in 1983 (when no nest-boxes were present) and 1984 (when nest-boxes were supplied in some of the patches). Because the magnitude of this variable clearly varied with patch area, the effect of the treatment was analysed with ANCOVA that included this factor as a covariate. Both patch area and difference in territory numbers were highly skewed towards low values and were $\log$ transformed before analysis.

\section{Results}

Great Tits were not found breeding in patches smaller than 0.19 ha (Table 1, Fig 1a). Above that area, there was a negative correlation between area and density (Fig. 1a). Using the average density in the ten smallest patches above 0.19 ha in area as null hypothesis, a total of five Great Tit territories (5.8 ha* 0.9 territories/ha) was expected in the smallest, now unoccupied patches. Correspondingly, a total of three ( $7 \mathrm{ha}^{*} 0.4$ territories/ha) Blue Tit and 1 (24.5 ha $* 0.03$ territories/ha) Pied Flycatcher territories were 
Table 1. Territories recorded in a set of 135 patches (0.01-24 ha large) where territories where mapped in 1982 and 1983 . There were no nest boxes in these patches. Comparing the two bottom rows gives an estimate of the number of territories expected in small patches if these were not avoided (see discussion).

\begin{tabular}{|c|c|c|c|}
\hline & Great Tit & Blue Tit & $\begin{array}{l}\text { Pied } \\
\text { Flycatcher }\end{array}$ \\
\hline Total number of territories $\mathrm{yr}^{-1}$ & 32 & 8 & 7.5 \\
\hline Smallest occupied patch (ha) & 0.19 & 0.23 & 1.0 \\
\hline $\begin{array}{l}\text { Aver. density in ten smallest patches (territories } \mathrm{ha}^{-1} \text { ) } \\
\text { with a size above that of the smallest occupied patch }\end{array}$ & 0.9 & 0.4 & 0.03 \\
\hline $\begin{array}{l}\text { Total area (ha) of all patches smaller than the } \\
\text { smallest occupied patch }\end{array}$ & 5.8 & 7.0 & 24.5 \\
\hline
\end{tabular}

expected in the smallest patches (Table 1, Fig. $1 \mathrm{~b}$ and c). The increase in density with decreasing patch size, down to a limit, was also observed for the Blue Tit (Fig. 1b) but not for the Pied Flycatcher (Fig. 1c).

\section{Effect of experimental nest box provisioning}

Great Tits bred in both small $(<1 \mathrm{ha})$ and large patches. The number increased in the experimental patches when nest-boxes were introduced but also in the control patches (Fig. 2a). When boxes were provided, Great Tits were found breeding in smaller patches than recorded in unmanipulated patches (minimum 0.19 ha). Thus, there were two breedings recorded in a 0.02 ha patch and one in a 0.05 ha patch (Fig. 3a). The pattern was similar for the Blue Tit (Fig. 2b), but the total number of territories recorded was less (15 vs 30) for the Great Tit (Fig. 2a and b). For this species, the minimum accepted patch size did not change when boxes were supplied (Fig. 3b). Almost no Pied Flycatcher nested in the small patches, regardless of nest box provisioning. In the larger patches there was a marked response to the addition of nest boxes (Fig. 2c).

The number of Great Tit territories increased or remained the same in all patches from 1983 to 1984 . However, in the control patches, the increase was less pronounced than in the experimental patches where nest boxes were supplied (Fig. 3a). The difference between control patches and experimental patches was significant (Table 2). There was not a clear pattern for the Blue Tit (Fig. 3b, Table 2). For the Pied Flycatcher there was no increase in the smaller patches, either in control patches or in experimental patches. However, in the larger patches, the increase was higher in the experimental patches (Fig. 3c), i.e. there was a significant interaction between patch area and patch treatment (Table 2).

\section{Discussion}

Few territories were expected in the low range of patch sizes where the species were lacking before nest boxes were provided. In the tit cases, this is because the total area of small, unused patches was small. Still, some territories were expected unless there were some effect of small patch size. For the Pied Flycatcher, the average density in occupied patches was low and the lack of territories in the small patches was not striking. For these reasons and for lack of an undisputable null hypothesis, I prefer not to formally test if the lack of the three species in smallest patches is significant. However, the fact that Tit density actually increased down to an area threshold at which they disappeared does suggest that at least these two species for some reason avoided the smallest patches in the present set. Several previous studies suggest similar patterns (Moore and Hooper 1975 (Great Tit), Opdam et al. 1985 (Pied Flycatcher), Nilsson 1986 (Great Tit), van Dorp and Opdam 1987 (Pied Flycatcher), Hinsley et al. 1996 (Great and Blue Tit), Berg 1997 (Blue Tit), and Kurosawa and Askins 2003 for forest edge bird species). The observed increase in patches just above the minimum size can probably be explained by the use of resources (e.g. food) in the surrounding matrix (Estades 2001). If matrix area exploited were included in territory area, territory size might well be less variable and not correlated with the size of the patch where the nest is situated.

Table 2. Experimental study. ANCOVA test of treatment and patch area effects on the change from 1983 to 1984 in number of territories. Both patch area and change were log transformed before analysis. For the tits, the interactions were not significant and removed before the final analysis.

\begin{tabular}{lccc}
\hline & DF & F & $\mathrm{p}$ \\
\hline Great Tit & & & \\
$\quad$ Area & $1: 31$ & 32.4 & $<0.001$ \\
$\quad$ Treatment & $1: 31$ & 5.11 & 0.031 \\
Blue Tit & & & \\
$\quad$ Area & $1: 31$ & 3.63 & 0.066 \\
Treatment & $1: 31$ & 0.42 & 0.53 \\
Pied Flycatcher & & & \\
Area & $1: 30$ & 6.41 & 0.017 \\
Treatment & $1: 30$ & 33.5 & $<0.001$ \\
Area*Treat & $1: 30$ & 27.0 & $<0.001$ \\
\hline
\end{tabular}


Great tit
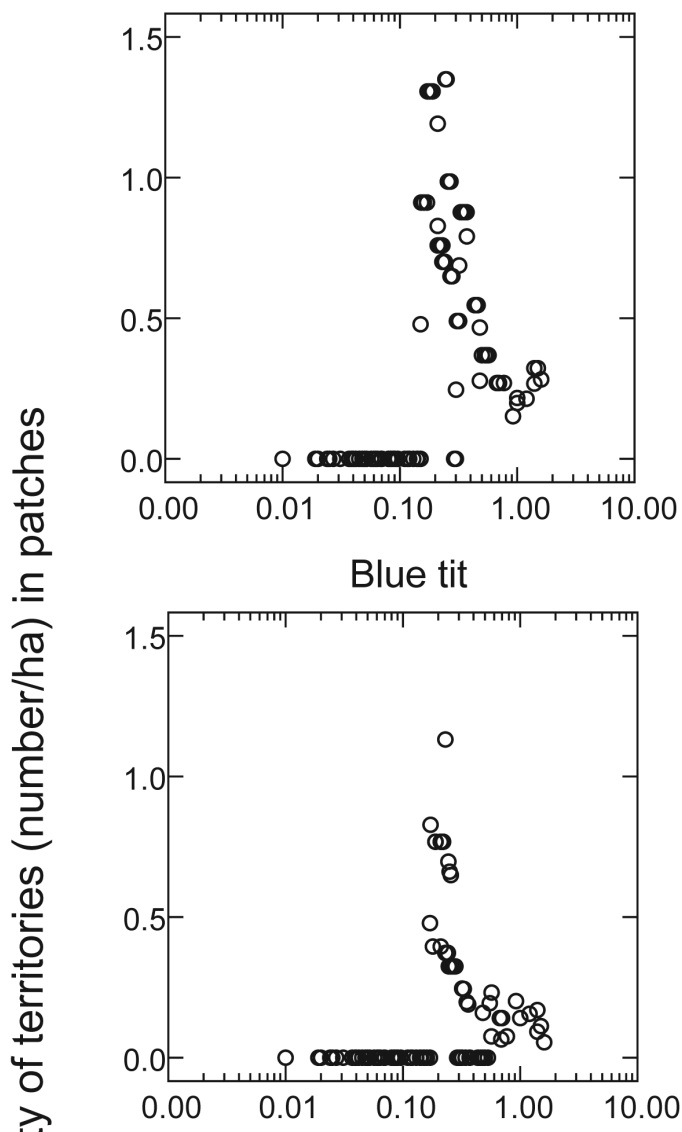

Pied flycatcher

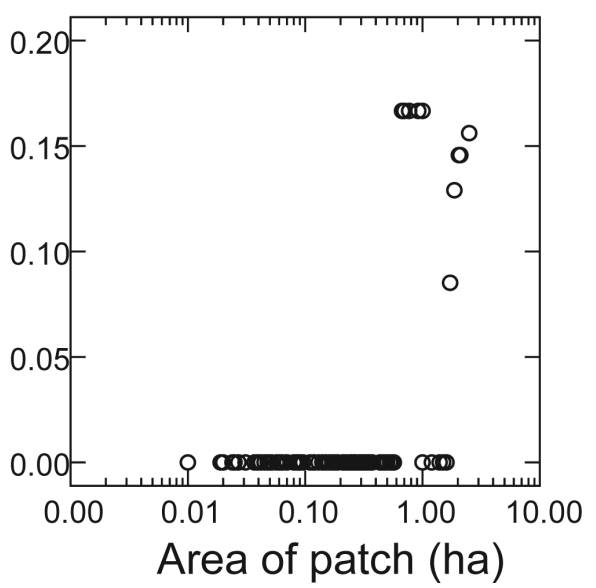

Fig. 1. Patch area and territory density of the three studied bird species. All 135 patches in the descriptive study are included. Patches are sorted by area; the symbols indicate the running average for each patch based on the patch and the five next larger and five next smaller patches. For the Pied fly catcher an average based on two larger and two smaller (rather than five) patches was used (otherwise the 10 largest patches that contained most Pied Flycatcher breedings would have been missing from the figure).
Great tit
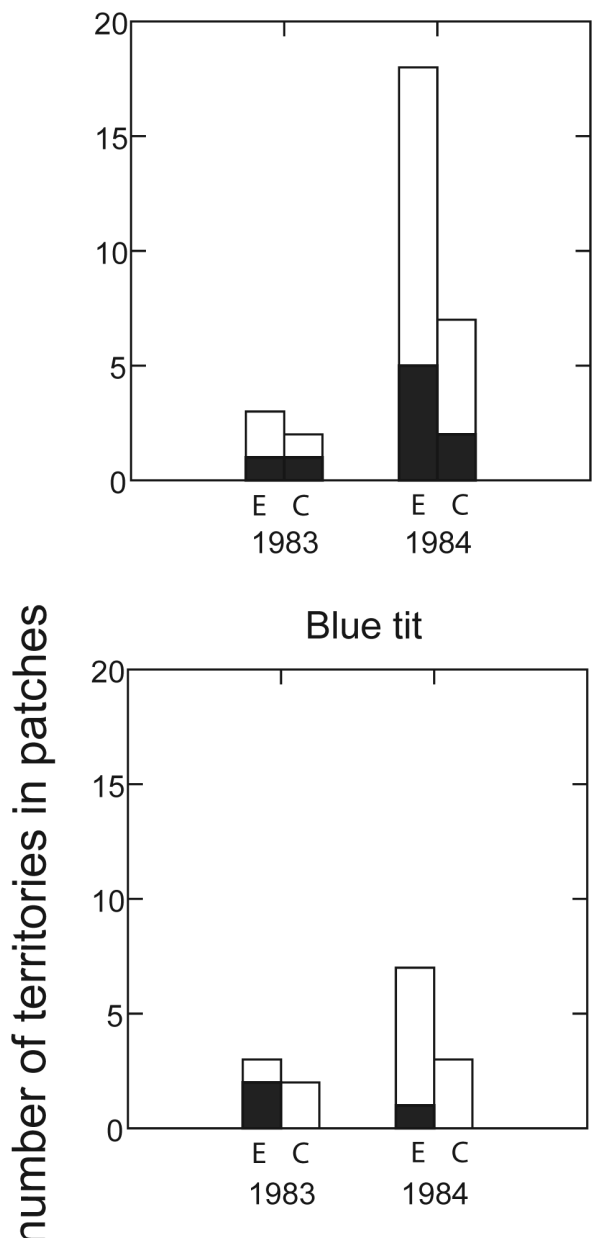

Pied flycatcher

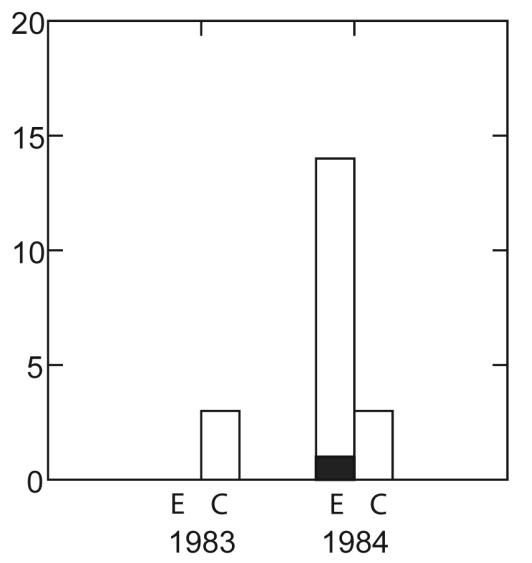

Fig. 2. Number of territories recorded in the 34 patches of the experimental study. $\mathrm{E}$ and $\mathrm{C}$ denotes experimental (with nestboxes in 1984) and control patches, respectively. The filled portion of the bars represents territories recorded in small patches $(<$ $1 \mathrm{ha}$ ). 
Great tit
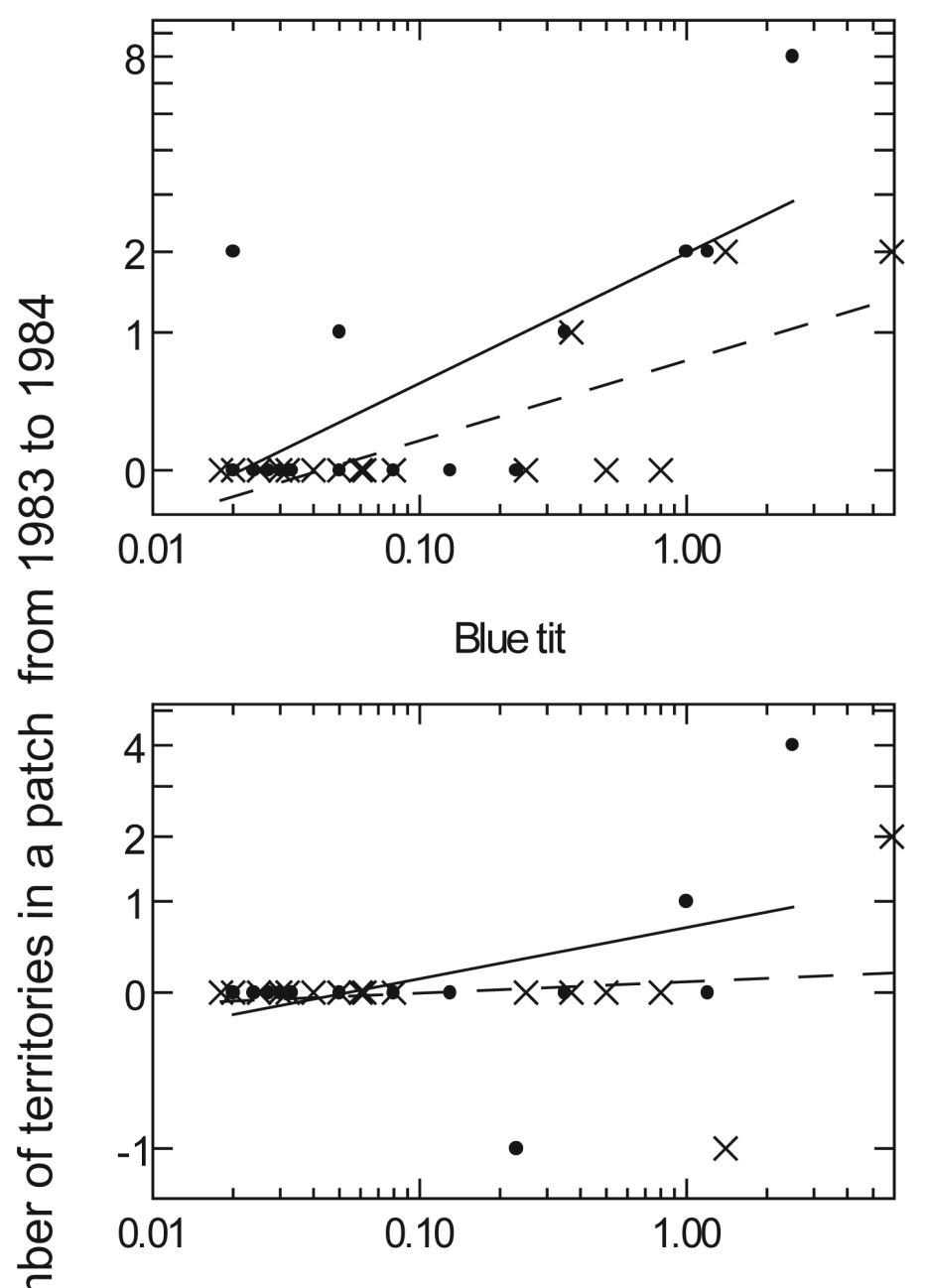

¿ Pied flycatcher

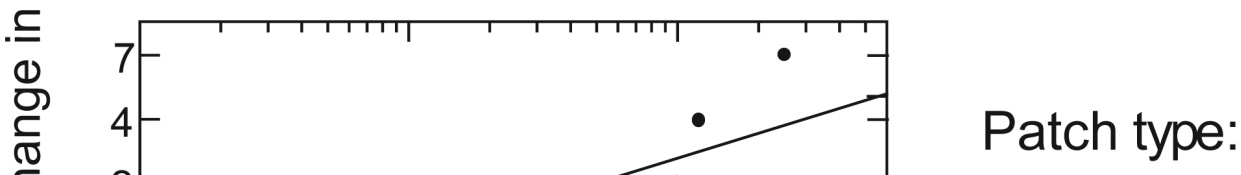

$\frac{\mathrm{C}}{\mathrm{U}}$

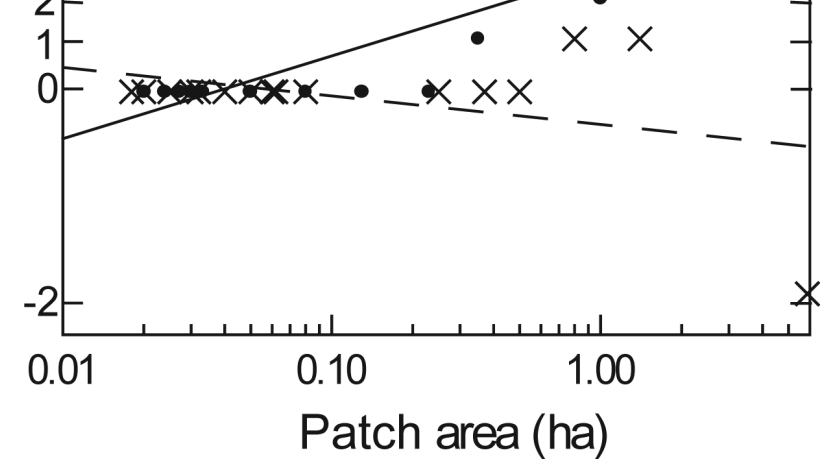

Experimental

Control $\times$

Fig. 3. Change in territory numbers from 1983 to 1984 . Each symbol represents one patch. 
For the Great Tit the number of territories increased by the addition of nest boxes, regardless of patch size. This suggests that breeding density was limited by nest site availability in all sizes of patches, including the very small ones. Actually, breeding by Great Tit was only recorded in patches $<0.1$ ha after nest boxes were supplied. There was no interaction which had confirmed a more marked response in small than large patches following nest box introduction. However, it suggests that a lack of nest sites is part of the picture in explaining the lower boundary of used patch areas. No consistent response was found for the Blue Tit. For the Pied Flycatcher, there was an effect of nest boxes in the larger patches only. This species did not seem to accept small patches, regardless of nest site availability. This hints that the lack of this species from small patches is not due to lack of nest sites. However, breeding density was clearly limited by nest sites in larger patches.

The density of nest boxes supplied differed between patches of different size. This was difficult to avoid because I wanted to span a fairly large range of patch sizes. The density used in the smallest patch (four boxes, at 200 boxes per ha) corresponded to a total of 987 boxes in the largest patch. Actually, 25 were used here. Can this have biased the results? The conclusion for the Pied Flycatcher is robust in this respect. Despite the high density of boxes, these were not used while the moderate increase in the large patches resulted in an increase in territories. In the Great Tit there was no effect of patch size. It is possible that a much higher number of boxes added to the larger patches would have resulted in a further increase in these patches. If so, one may have concluded that the abundance of nest sites was more limiting in large than in small patches. However, the present results show that, regardless of relative magnitude of the effect, nest sites were limiting in both small and large patches for Great Tits. The two largest patches contained in 1984 a total of 25 and 12 boxes, respectively. Out of these 20 and seven, respectively, were occupied. Assuming that nest sites were limiting, it can not be ruled out that the empty boxes were unsuitable for either of the species, e.g. too close to conspecifics. If so, a higher number may have resulted in even more Great Tits in these large patches. Nevertheless, this does not invalidate the main conclusion.

Providing nest boxes has increased the density of holenesters in many previous studies (Brawn and Balda 1988, Newton 1994, Bock and Fleck 1995), although a study on flying squirrels failed to find an effect (Brady et al. 2000). With regard to the species addressed here, other studies where nest boxes have been supplied have found an increase in breeding tits (Higuchi 1978) and Pied Flycatcher (Enemar and Sjöstrand 1972, Järvinen 1978, Currie and Bamford 1982). Alerstam (1985) found a similar increase in densities of Great Tits and Pied Flycatcher in a small deciduous wood (12 ha) but no corresponding increase in Blue Tits. His hesitation to attribute this finding to competition from Great Tits is supported by the present study where $50 \%$ of the boxes had small holes and were not used by Great Tits. However, competition between the two species has been suggested (Dhondt and Eyckerman 1980). It is possible that competition from Great Tits, at least proximately for other reasons than nest sites, limited the number of Blue Tits. If so, this was even more so after the increase in Great Tits following nest box provisioning. It is also possible that the Blue Tits actually preferred boxes with large holes (Kempenaers and Dhondt 1991) and the reduction of these caused by Great Tits was enough to deter Blue Tits.

The nest site limitation hypothesis did not explain the lack of Flycatchers in small patches and only with some hesitation that of the two Tit species. Are there alternatives to lack of nest sites for the avoidance of small habitat islands by Tits and Flycatchers? It may be that these forest species cannot find sufficient food in a very small forest patch. Indeed, breeding performance in small forest patches has been found to be poorer than that in larger forests for Great and Blue Tits (Hinsley et al. 1999), although other studies found no difference for the Tits (Nour et al. 1998) and Flycatchers (Huhta and Jokimäki 2001). There is also evidence that predation may be higher in small habitat fragments (Möller 1991, Paton 1994, Batáry and Báldi 2004). The latter fact is of particular interest here because there is evidence that predation is higher on nests in natural cavities than in nest boxes (Mitrus 2003). If nest sites are limiting in some habitat patches, maybe one should stress safe nest sites. In the study area, breeding performance of Great Tits was indeed poorer in the small patches (Loman 2003). Matthysen and Currie (1996) found that Nuthatches (Sitta europea) were more reluctant to colonize territories that were vacant but previously had proven suitable in small patches than such territories in larger woods. They attributed this to risks and time cost involved in prospecting these sites. These two alternative explanations may well have been part of the picture also in this study area. However, at least for the Great Tit, it gives support to the hypothesis that nest sites may be limiting in very small patches.

Acknowledgements - Valde Holmgren, Anders Jonsson, Nils Kjellén, Jan-Åke Nilsson, Olof Persson and Henrik Smith helped with field work. The presentation has been improved by comments from Henrik Smith. The work was financed by the $\mathrm{Na}$ tional Swedish Environment Protection Board.

\section{References}

Anon. 1970. Recommendations for an international standard for a mapping method in bird census work. - Bull. Ecol. Res. Committee 9: 49-52.

Alerstam, T. 1985. Fåglarna i Borgen. - Skånes Natur 72: 115125.

Andrén, H. 1994. Effects of habitat fragmentation on birds and mammals in landscapes with different proportions of suitable habitat: a review. - Oikos 71: 355-366. 
Angelstam, P. 1992. Conservation of communities - The importance of edges, surroundings and landscape mosaic structure. - In: Hansson, L. (ed.), Ecological Principles of Nature conservation. Elsevier, pp. 9-70.

Batáry, P. and A. Báldi. 2004. Evidence of an edge effect on avian nest success. - Conserv. Biol. 18: 389-400.

Bellamy, P. E., Hinsley, S. A. and Newton, I. 1996. Factors influencing bird species numbers in small woods in south-east England. - J. Appl. Ecol. 33: 249-262.

Berg, A. 1997. Diversation and abundance of birds in relation to forest fragmentation, habitat quality and heterogeneity. Bird Study 44: 355-366

Blake, J. G. and Karr. J. R. 1984. Species composition of bird communiites and the conservation benefit of large versus small forests. - Biol. Conserv. 30: 173-187.

Bock, C. E. and Fleck. D. C. 1995. Avian response to nest box addition in two forests of th Colorado Front Range. - J. Field Ornith. 66: 352-362.

Brady, M. J., Risch, T. S. and Dobson. F. S. 2000. Availability of nest sites does not limit population size of southern flying squirrels. - Can. J. Zool. 78: 1144-1149.

Brawn, J. D. and Balda. R. P. 1988. Population biology of cavity nesters in norhtern Arizona: do nest sites limit breeding densitites? - Condor 90: 61-71.

Cieslak, M. 1985. Influence of forest size and other factors on breeding bird species number. - Ekol. Polska 33: 103-121.

Currie, F. A. and Bamford. R. 1982. Songbird nest-box studies in forests in north Wales. - Quar. J. Forestry 76: 250-255.

Dhondt, A. A. and Eyckerman. R. 1980. Competition and the regulation of numbers in great and blue tit. - Ardea 68: 121132.

Enemar, A. and Sjöstrand. B. 1972. Effects of the introduction of pied flycatchers Ficedula hypoleuca on the composition of a passerine bird community. - Ornis Scand. 3: 79-87.

Estades, C. F. 2001. The effect of breeding-habitat patch size on bird population density. - Landscape Ecol. 16: 161-173.

Evans, K. L. 2004. The potential for interactions between predation and habitat change to cause population declines of farmland birds. - Ibis 146: 1-13.

Higuchi, H. 1978. Use of nest-boxes by birds according to forest types and the breeding density in forests with and without nest-boxes. - J. Japan. Forestry Soc. 60: 255-261.

Hinsley, S. A., Bellamy, P. E., Newton, I. and Sparks, T. H. 1996. Influences of population size and woodland area on bird species distribution in small woods. - Oecologia 105: 100-106.

Hinsley, S. A., Rothery, P. and Bellamy, P. E. 1999. Influence of woodland area on breeding success in Great Tits Parus major and Blue Tits Parus caeruleus. - J. Avian Biol. 30: 271281.

Huhta, E., Jokimäkei, J. and Rahko, P. 1998. Distribution and reproductive success of the pied flycatcher Ficedula hypleuca in relation to forest patch size and vegetation characteristics; effect of scale. - Ibis 140: 214-222.
Huhta, E. and Jokimäki, J. 2001. Breeding occupancy and success of two hole-nesting passerines: the impact of fragmentation caused by forestry. - Ecography 24: 431-440.

Järvinen, A. 1978. Nest-box studies in a mountain birch forest at Kilpisjärvi, Finnish Lapland. - Anser suppl. 3: 107-11.

Kempenaers, B. and Dhondt, A. A. 1991. Competition between blue and great tit for roosting sites in winter an aviary experiment. - Ornis Scand. 22: 73-75.

Kurosawa, R. and Askins, R. A. 2003. Effects of habitat fragmentation on birds in deciduous forests in Japan. - Conserv. Biol. 17: 695-707.

Loman, J. 2003. Small habitat islands are inferior breeding habitats but are used by some great tits - competition or ignorance? - Biodiv. Conserv. 12: 1467-1479.

Loman, J. and von Schantz, T. 1991. Birds in a farmland more species in small than in large habitat island. - Conserv. Biol. 5: 176-188.

Matthysen, E. and Currie, D. 1996. Habitat fragmentation reduces disperser success in juvenile nuthatches Sitta europea: evidence from patterns of territory establishment. - Ecography 19: 67-72.

Mitrus, C. 2003. A comparison of the breeding ecology of collared flycatchers nesting in boxes and natural cavities. - J. Field Ornith. 74: 293-299.

Möller, A. P. 1991. Clutch size, nest predation and distribution of avian unequal competitors in a patchy environment. - Ecology 72: 1336-1349.

Moore, N. W. and Hooper, M. D. 1975. On the number of bird species in British woods. - Biol. Conserv. 8: 239-250.

Newton, I. 1994. The role of nest sites in limiting the numbers of hole-nesting birds: A review. - Biol. Conserv. 70: 265-276.

Nilsson, S. G. 1986. Are bird communities in small biotope patches random samples from communities in large patches? - Biol. Conserv. 38: 179-204.

Nilsson, S. G. and Ericson, L. 1992. Conservation of plant and animal populations in theory and practice. - In: Hansson, L. (ed.), Principles of Nature conservation. Elsevier, pp. 71112.

Nour, N., D. Currie, D., Matthysen, E., Van Damme, R. and Dhondt, A. A. 1998. Effects of habitat fragmentation on provissioning rates, diet and breeding success in two species of tit (great tit and blue tit). - Oecologia 114: 522-530.

Opdam, P., Rijsdijk, G. and Hustings, F. 1985. Bird communities in small woods in an agricultural landscape: effects of area and isolation. - Biol. Conserv. 34: 333-352.

Paton, P. W. 1994. The effect of edge on avian nest success: How strong is the evidence? - Conserv. Biol. 8: 17-26.

Thompson III, F. R., Donovan, T. M., Degraaf, R. M., Faaborg, J. and Robinson, S. K. 2002. A multi-scale perspective of the effects of forest fragmentation on birds in eastern forests. Studies Avian Biol. 25: 8-19.

van Dorp, D. and Opdam, P. F. M. 1987. Effects of patch size, isolation and regional abundance on forest bird communities. - Landscape Ecol. 1: 59-73. 